\title{
SENSORY ACCEPTABILITY OF COOKIES FORTIFIED WITH TILAPIA FISH BONE POWDER
}

\author{
https://doi.org/10.37512/800 \\ Received 14.06.2020, Reviewed 24.08.2020, Accepted 26.09.2020. \\ *Joseph G. Njoroge ${ }^{1}$, Michael N.I. Lokuruka ${ }^{1}$ \\ ${ }^{1}$ Department of Food Science and Nutrition, School of Agriculture and Biotechnology, Karatina \\ University, Box 1957-10101, Karatina, Kenya. \\ E-mail:joegaithumajoe@gmail.com; mlokuruka@gmail.com; mlokuruka@karu.ac.ke \\ *Corresponding author: Joseph G. Njoroge: joegaithumajoe@gmail.com
}

\begin{abstract}
A large percentage of fresh tilapia fish, including bone, is inedible and largely considered as waste. In order to find some use for waste fish bone, this study was conceived and conducted. Its aim was to determine the sensory acceptability of cookies to which tilapia fish bone powder has been added, and the potential for cookies to deliver calcium to consumers. It also aimed at analyzing the calcium content of control and experimental samples of cookies. Wheat grains were cleaned, dried and milled. The tilapia fish was boiled and the flesh removed by hand and the bones rinsed with tap water. The fish frame was boiled with $2 \% \mathrm{NaOH}$ solution in the ratio 1:5 (fish frame to $\mathrm{NaOH}$ ) at $80-90^{\circ} \mathrm{C}$ for $30 \mathrm{~min}$ at an adjusted $\mathrm{pH}$ of 6.2. Further processing with $0.1 \%$ citric acid removed the fishy aroma, while $5 \%$ hydrogen peroxide solution was used as disinfectant. The bones were dried in an oven at $100{ }^{\circ} \mathrm{C}$ for 3 hours and ground. The fortification of $0.5 \mathrm{~kg}$ of wheat flour was done with $1 \mathrm{~g}, 5 \mathrm{~g}$ and $10 \mathrm{~g}$ of fish bone powder. The control sample did not contain fish bone powder. The samples were baked and the cookies used for the organoleptic tests. Calcium content in the cookies was determined using an Atomic Absorption Spectrophotometer at a wavelength of $422.67 \mathrm{~nm}$. A nine-point hedonic scale was used for the sensory evaluation of the taste, colour and mouthfeel of the cookies. The results showed that the Calcium content of the cookies increased with addition of fish bone powder. The dried fish bone powder contained approximately $100 \mathrm{mg}$ of calcium/1000 mg of fish bone powder. The most liked cookie (average weight of 20 grammes) had a calcium content of $40 \mathrm{mg}$ and therefore twenty-five of them would be required to supply the $1000 \mathrm{mg}$ RDA of an adult person. The sample fortified with $2 \%$ fish bone powder was rated the best by the panelists overall for the three sensory attributes assessed. Therefore, fish bone fortified cookies are sensorially acceptable at $2 \%$ fortification level and can be consumed as a supplementary food for dietary calcium delivery.
\end{abstract}

KEY WORDS: Tilapia fish-bone powder, calcium, cookies, sensory assessment 


\section{INTRODUCTION.}

Tilapia is a good source of protein and is also a popular fish in commercial fisheries whose production in Kenya has been gradually increasing. Tilapia is one of several commercially important aquaculture species that are relatively inexpensive to rear, thus making it accessible to consumers (De Silva et al., 2008). Tilapia tends to have low levels of mercury (Hemung, 2013), as they are fastgrowing, lean, with a primarily vegetarian diet. They do not therefore accumulate mercury found in the prey which may alter the taste and the smell of their products. Whole tilapia can be processed into skinless and boneless fillets. The yield of these processes has been reported to be in the range of 30$37 \%$, depending on fish size and trimming process (Toppe et al., 2007). Thereafter, the rest of fish are regarded as waste or by-products. These parts include bone, skin, protein from skin and other wasted parts, scale, fat, and blood. Bone is the main component of the by-products, accounting for about $10-15 \%$ of total fish weight (Toppe et al., 2007). Bone is also a source of important minerals: sodium, phosphorous, and calcium. Tilapia fish are low in calories, carbohydrates, and sodium, and are a good protein source (Hemung, 2013). Fish bones have a high mineral content including 34-36\% Calcium, mainly as Calcium phosphate which may serve as a dietary source of Calcium and Phosphorus (Malde et al., 2010). Calcium ion $\left(\mathrm{Ca}^{2+)}\right.$ is important for the development of the human bone and teeth, particularly in an infant. Utilization of fish bone can be a natural source of $\mathrm{Ca}^{2+}$ supplementation (Johnson et al., 2007). This would be a strategy to maximally utilize fish resource as well as to effectively reduce the waste from the fishery industry. In recent years, emphasis has been put on producing high quality nutritional products from fish by-products. Most of the by-products are used as low-quality raw materials for feed production and/or are dumped into the sea. Recent estimates revealed that current discards from the world's fisheries exceed 20 million tons, which is equivalent to $25 \%$ of the total production of marine capture fisheries. Thus, scientific documentation of content and use of various components from marine by-products for human consumption is warranted (Kim et al., 2000b). However, very little information is available on the beneficial effects of use of fish bone although few attempts have been made to find ways to use them for the benefit of human health. To incorporate fish bone into calcium-fortified food, it should be converted into an edible form by softening it (Nemati et al., 2017). This can be achieved by hot water treatment. (Ishikawa, et al., 1990)

Although there are many sources of calcium in the diet, calcium deficiency has been found in the Kenyan population especially in the most susceptible groups: infants, pregnant /lactating mothers and the elderly (Pettifor, 2014). In 2011, 1.1 billion people in the World were at risk of calcium deficiency (Dirida et al., 2015). This creates a need to find ways of supplementing or fortifying foods that are available to a large proportion of the human population. Assessments of Kenyan diets established that Calcium intakes of 200-300 mg/day are common compared to the daily RDA of 1000mg (Pettifor, 2014). Dairy product intake is minimal in many Kenyan communities and typical diets also contain high amounts of phytates, oxalates and tannins that are likely to reduce the absorption of calcium (Pettifor, 2014). This creates the need to fortify a variety of food stuffs. Cookies are available in a variety of flavors and are a common snack for different age groups including the elderly who are at a higher risk of calcium deficiency due to poor dietary habits. Cookies are therefore a good candidate food for fortification. 


\section{OBJECTIVE}

This study aimed at investigating sensory acceptability of cookies fortified with tilapia fish bone powder (TFBP).

\section{MATERIALS AND METHODS}

\section{Sample acquisition and preparation}

Both wheat grains and tilapia fish were purchased from Karatina town. Each sample was prepared separately and later the tilapia fish bone powder was added to the wheat flour at three levels.

Commercial wheat flour was not used since it is already fortified with micro nutrients (Akhtar, 2011) which could have altered the results of the study. Wheat grains were sorted to remove foreign matter and contaminated grains. Impeccable grains were dry cleaned through winnowing to remove dust and other contaminants. After cleaning, the wheat grains were packaged in a clean bag and were later milled. The flour obtained was packaged in a dry clean bag and sealed to avoid moisture uptake from the surrounding storage space. Whole Tilapia fish were obtained from Karatina town and were boiled at the school workshop and the flesh was removed by hand and the bones were rinsed with tap water to remove any extraneous matter. The fish bones were prepared by boiling the fish frame with alkali$2 \% \mathrm{NaOH}$ solution, in the ratio of 1:5 (Fish frame to $\mathrm{NaOH}$ ) at $80-90^{\circ} \mathrm{C}$ for $30 \mathrm{~min}$. The $\mathrm{pH}$ was adjusted to 6.2 so as to maintain the bone taste and quality; further processing with $0.1 \%$ citric acid for aroma removal and $5 \%$ hydrogen peroxide for disinfection were done. It was dried in an oven at $100{ }^{\circ} \mathrm{C}$ for about 3 hours to remove water from the bone. The bones were then ground using a grinder until a fine powder was obtained. The powder was then packed in an air tight bag, sealed and kept at room temperature for 24 hours before calcium analysis was carried out.

\section{Cookie flour preparation}

Three samples of $0.5 \mathrm{~kg}$ of wheat flour each were fortified with fish bone powder with $1 \mathrm{~g}, 5 \mathrm{~g}$, and $10 \mathrm{~g}$ consecutively. The control sample of the wheat flour was not fortified with the tilapia fish bone powder. The formulations targeted achieving an acceptable dietary calcium delivery for the target consumers and of good sensory acceptability. The four samples were labeled as: A (control), B, C and D. Cookies were made from each of the formulations.

\section{Calcium estimation.}

An Atomic Absorption Spectrophotometer (model 210 VGP Buck Scientific Inc. East Norwalk, USA was used to determine the calcium content in the tilapia fish bone powder (TFBP), the control sample and the 3 samples with fish powder, at a wavelength of $422.7 \mathrm{~nm}$. The calcium content of the cookies was determined using the Atomic Absorption Spectrophotometer as follows: the sample was ashed and then dissolved in an aqueous solution, placed in the instrument where it was heated to vaporize 
and atomize the minerals. A beam of radiation was passed through the atomized sample, and the absorption of radiation was measured at a wavelength of $422.7 \mathrm{~nm}$. Information about the type and concentration of calcium present was obtained by measuring the location and intensity of the peaks in the absorption spectra (Minitab, 2010). The method described in the instrument's manual was used to adjust the lamp and other parameters of the instrument to give optimal absorbance signal as advised by the manufacturer. Three absorption readings were taken for each solution of samples and the value for the closest two readings was averaged and used. Absorbance was recorded in a table and a plot of concentration against absorbance was plotted. Samples were run in triplicate and absorbance corrected for background signal (Minitab, 2010). Data was collected and recorded in an Excel Computer Software for calcium estimation.

\section{Sensory evaluation.}

The cookies were coded with an alphabetical letter and served to 50 trained panelists in a sensory booth with adequate lighting, quiet environment and 1 meter spacing between them. The panelists were first taken through the consent form to get their consent to take part in the evaluation. They were also shown on how to fill in the responses in the forms provided for each sample. They were provided with the 4 sample for evaluation and a glass of water each to reduce the carry-over tastes between samples. They were asked to score the cookie samples for colour, taste and mouthfeel and their overall liking. The scoring was based on a 9-point hedonic scale, where 9 represented "extremely like" and 1 for "extremely dislike" (Table 1).

Limitations of the study: Due to the limited time and finance, the study did not analyze the content of other minerals of nutritional and health significance in the cookies.

\section{Data analysis}

The calcium content data and sensory evaluation data was analyzed using Microsoft Excel for the mean and standard error of and deviation of the mean.

\section{RESULTS AND DISCUSSION}

\section{Sensory attributes of cookies fortified with fish bone powder}

The lowest score in taste, texture and overall liking was found with cookies enriched with $1 \%$ tilapia fish bone powder (TFBP). When compared with the other cookies, enrichment level of $2 \%$ produced no significantly different reaction from the participants with regard to the three attributes assessed. Therefore, the level of fortification $(0.2,1.0$ and 2.0) did not alter the attributes significantly as to alter the acceptability of even sample D. However, panelists preferred cookies enriched with $2 \%$ tilapia fish bone powder and therefore gave it the overall rating of 8.2 (Table 1). 
Table 1: Score for Sensory characteristics of cookies fortified with TFBP

\begin{tabular}{lllll}
$\begin{array}{l}\text { Fortification } \\
\text { level }\end{array}$ & Colour & Taste & Mouthfeel & Overall liking \\
\hline $0 \%$ Control (A) & $8.1 \pm 1.22$ & $5.7 \pm 1.31$ & $6.9 \pm 1.10$ & $6.9 \pm 0.99$ \\
$0.2 \%$ TFBP (B) $8.7 \pm 1.16$ & $8.3 \pm 1.11$ & $7.0 \pm 1.03$ & $8.0 \pm 0.82$ \\
$1 \%$ TFBP (C) & $5.1 \pm 1.08$ & $8.0 \pm 1.29$ & $6.8 \pm 1.44$ & $6.6 \pm 1.22$ \\
$2 \%$ TFBP (D) & $8.4 \pm 1.21$ & $8.8 \pm 1.37$ & $7.5 \pm 1.59$ & $8.2 \pm 1.39$ \\
\hline
\end{tabular}

Legend: 1. the hedonic scale had the narration: 1-dislike extremely; 2-dislike very much; 3-dislike moderately; 4-dislike slightly; 5-neither like nor dislike; 6-like slightly; 7-like moderately; 8-like very much; 9-like extremely.

2. The scores used in Table 1 are the modes for each attribute.

The sample with $0.2 \%$ TFBP was rated the best in terms of colour. The bone fish powder in this study was creamy while that of wheat flour was white. Due to the expected colour change, the light colour of the cookies as observed in the control sample decreased with the addition of fish bone powder. The carbohydrate and protein in the bone powder enables the nutrients take part in non-enzymatic browning reactions-Maillard reaction and caramelization during baking (Asikin et al., 2019). This explains the darkening of the cookies with higher fortification with TFBP. Therefore, the change in colour from a bright white colored cookie to dark grey cookies was observed with the addition of increasing amount of fish bone powder. The higher calcium content with higher fortification with TFBP makes the mix less soluble in water. The increasing calcium content results in change of colour of the cookies, as a result of the reduced amount of light that can pass through the bone powder (Asikin et al., 2019). Sample B scored the highest for colour, as it proved to be a good balance between the whiteness of the wheat flour and the browning effect caused by the TFBP and any contribution from protein and carbohydrate in wheat flour. The results were contrary to those of Sirichokworrakit et al. (2014), who indicated that the product with $1 \%$ bone powder received the highest overall acceptability.

The tensile strength of the cookies, which decreased with fortification, was significantly different between samples. This could be due to the bone powder diluting the gluten strength in the wheat powder and interrupting the structure of the cookies thus producing a better and crunchy mouthfeel. Increasing fortification with fish bone powder increased the hardness of the cookies. This is due to the fact that the bone powder requires a lot of water to obtain a perfect dough and the dough had a harsh consistency. This was observed as increased hardness in comparison to the cookies made from the control. The cookies from the $2 \%$ TFBP level of fortification also had the lowest level of fracturability compared to the other samples. These observations are similar to the findings of Asikin et al. (2019), who showed that the addition of Tuna fish bone powder to dough resulted in wheat crackers developing a harder texture than the crackers made from the control. As bone powder is hygroscopic and absorbs water from the environment, which increases the moisture content of the cookies, the bone particles bind better on moisture uptake. This probably explains why the panelists had better reaction towards the taste of the samples. Mustofa et al. (2011) found that decreasing the particle size of the fish bone (by milling) resulted in a better taste of cookies. 
Considering the mean rating of color, the color for the sample coded B was the best followed by A then D (Table 1) and the poorest was sample C. Looking at the taste, D was rated as the best sample followed by A, B and finally C. Sample D had a better mouth feel when compared with other samples, which may have contributed to the best overall liking. Sample $C$ was rated the poorest in terms of texture (Table 1).

\section{Calcium content of cookies and the control sample}

Analysis showed that the sample with a $2 \%$ fortification with TFBP (sample D) contained the highest amount of calcium $(189.118 \mathrm{mg} / 100 \mathrm{~g}$ ) compared to the other samples. The control sample (sample A) had $41.347 \mathrm{mg} / 100 \mathrm{~g}$ of TFBP. It was evident that calcium content of the cookies increased with increasing fortification with TFBP of the wheat flour. Calcium content of the cookies was directly proportional to the amount of fishbone powder added to the wheat flour. The results of the study were similar with those of Abdel-Moemin (2015), who showed that enriched cookies improved the sensory attributes with the best scores being at $2 \%$ level of fortification followed by the $0.2 \%$. The amount of calcium in samples is shown in Table 2.

Table 2: Calcium content of samples

\begin{tabular}{|l|l|}
\hline Sample & Mean $(\mathbf{m g} / \mathbf{1 0 0 g})$ \\
\hline Sample A & $41.347 \pm 0.747$ \\
\hline Sample B & $73.075 \pm 0.779$ \\
\hline Sample C & $125.320 \pm 3.413$ \\
\hline Sample D & $189.118 \pm 3.787$ \\
\hline
\end{tabular}

Legend: sample A-control sample without any TFBP; B, C and D-experimental cookie samples

\section{CONCLUSION}

From the study, it was established that 1 gramme of the dried tilapia fish bone powder (TFBP) contained approximately $100 \mathrm{mg}$ of calcium. Fortifying wheat flour for making cookies with $2 \%$ TFBP can provide $20 \%$ of adult RDA of calcium (1000 mg/daily) from consuming 5 cookies. The cookies from the $2 \%$ fortification level were of acceptable sensory quality and can be consumed as a supplementary food for the delivery of dietary calcium.

\section{Recommendations}

Further research work to determine the shelf life of cookies fortified with fish bone powder is recommended. We also recommend a further study to determine other minerals in the cookies and possibly even the vitamins of nutritional significance in calcium metabolism. 


\section{Nature of Project}

This was a B. Sc. Honours in Food Science and Nutrition student project of Karatina University

\section{REFERENCES}

Abdel-Moemin. (2015). “Healthy cookies from cooked fish bones. ' Food Bioscience Vol.12: $114-121$.

Allen, L.H. (1982). "Calcium bioavailability and absorption": a review. Am. J. Clin. Nutr. 35: 738808.

Asikin A N, Kusumaningrum I and Hifayat, T. (2019). "Effect of Knife-fish bone powder addition on characteristics of starch and seaweed kerupuk as calcium and crude fiber sources". Curr. Res. Nutr. Food Sci. 7(2): 584-591.

Diriba B. Kumssa, Edward J. M. Joy and Martin R. Broadley. (2015). "Dietary calcium and zinc deficiencies are decreasing but remain prevalent.' Sci. rep.5, 10974.

Found at: https://doi.org/10.1038/srep10974, 2-6

Hemung Bung-Orn. (2013). "Properties of tilapia bone powder and its calcium bioavailability based on transglutaminase assy." IJBBB; 3(4): 306-308.

Ishikawa, M., Kato, M., Mihori, T., Watana, H. and Sakai, Y. (1990). "Effect of vapor pressure on the rate of softening of fish bone by super-heated steam cooking". Nippon Suisan Gakkaishi 56: 1687-1691.

J. Toppe, S. Albrektsen, B. Hope, and A. Aksnes. (2007). "Chemical composition, mineral content and amino acid and lipid profiles in bones from various fish species," Comparative Biochemical and Physiology Vol. 146B: 395-401.

Johnson, R.B.; Nicklason, P.M. and Barnett, H.J. (2003). "Macro- and micronutrient composition of fish bone derived from Alaskan fish meal processing: exploring possible uses for fish bone meal," In: P.J. chtel (ed.), Advances in Seafood Byproducts. Conference Proceedings. Alaska Sea Grant College Program. Fairbanks, Alaska, p. 566.

Kim, J.; Yang, S. and Heu, M. (2000b). "Component characteristics of cooked tuna bone as a food source". Journal of Korean Fishing Society 33: 38-42.

M. K. Malde, S. Bugel, M. Kristensen, K. Malde, I. E. Graff, and J. I. Pedersen. (2010). "Calcium from salmon and cod bone is well absorb in young healthy men: a double-blinded randomized crossover design. Nutrition and Metabolism Vol. 7(61): 1-9.

Malde. M. K, Graff, I.E, Siliander-Rasi. H, Pedersen, J. and Valaja, J. (2010). "Fish bone-a highly Available calcium source for growing pigs." J. Anim. Phys. Anim. Nutr. 94(5): 66-76.

Minitab 17 Statistical Software. (2010). Computer Software. State College, PA, USA: Minitab, Inc. Found at: www.minitab.com.

Mustofa, K.A. and Suyamto, A. (2011). "Effect of the addition of flour shell crab variation on calcium, the ability to swell and organoleptic properties of onggok cassava's crackers" Journal Pangan Dan Gizi. 2(3):1-14. 
Nemati. M, Nurul Huda, and F. Ariffin. (2017). "Development of calcium supplement from fish bone wastes of yellowfin tuna and characterization of nutritional quality” IFR Journal 24(6): 2419-2426)

Pettifor, J.M. (2014). "Calcium and vitamin D metabolism in children in developing countries." Ann Nutr. Metab. (suppl. 2): 15-22

Sirichokworrakit, Supatchalee, Juthamat Phetkhut, and Anuntachai Khommon. (2015). "Effect of partial substitution of wheat flour with riceberry flour on quality of noodles. Procedia-Social and Behavioral Sciences 197:1006-1012

Saeed Akhtar, Faqir M. Anjum, M. and Akbar Anjum. (2011). "Micronutrient fortification of wheat flour: recent development and strategies.” Food Research International. Vol. 44(3): 622-659, published April 2011.

S. S. De Silva, R. P. Subasinghe, D. M. Bartley, and A. Lowther. (2008). "Tilapia as alien aquatics in Asia and the Pacific: A review," FAO Fisheries Technical Paper, no. 455.

Toppe, J.; Aksnes, A.; Hope, B. and Albrektsen, S. (2007). "Inclusion of fish bone and crab by-products in diets for Atlantic cod, Gadus morhua". Aquaculture 253: 636-645. 